\title{
La construcción de la pertenencia socioterritorial: el caso de Jurica, un pueblo al que le llegó la ciudad*
}

I. Introducción

Hasta los años ochenta la antropología urbana estudió la urbanización generada por el crecimiento económico y su expansión de las ciudades a partir de la migración rural-urbana, pero poca atención se puso a la otra cara de la moneda, al proceso inverso, es decir, a los pueblos a los que les "llegó" la ciudad. El presente artículo trata sobre un pueblo que se ubica al norte de la ciudad de Querétaro, el estudio de caso de Jurica resultó ser un buen ejemplo para dar cuenta de las diversas maneras como se trasforma el entorno natural debido a las actividades urbano-industriales. Particularmente me interesa analizar la relación entre territorio y cultura ya que a partir de esta es posible distinguir referentes identitarios, los cuales se (re)construyen en un marco espacial y temporal que se transforma conforme avanza la expansión metropolitana.

Palabras clave: Urbanización, espacio, cultura, pertenencia socioterritorial,

identidad.

- Profesora-investigadora de la Facultad de Ciencias Políticas y Sociales de la Universidad Autónoma de Querétaro

lorenaosorio030@hotmail.com setenta, pero ha cobrado mayor fuerza en los últimos años debido principalmente a la urbanización y el crecimiento de las ciudades. Este fenómeno no es privativo de las grandes áreas metropolitanas como la ciudad de México o Guadalajara, también se puede observar en ciudades medias como Querétaro.

A partir de los años setenta la entidad queretana tuvo un importante y creciente desempeño económico vinculado estrechamente a la industrialización ocurrida en el marco de las políticas federales de desarrollo de la industria nacional para la sustitución de importaciones. La estratégica ubicación geográfica de la ciudad de Querétaro y su cercanía con la ciudad de México

\footnotetext{
*El presente artículo se deriva de un trabajo de investigación más amplio que realicé durante 2010 y $201 \mathrm{I}$ para obtener el grado de doctora en antropología social. Agradezco la lectura y los comentarios de la Dra. Patricia Safa Barraza.
} 
fueron factores primordiales que contribuyeron y estimularon el asentamiento industrial. La creación de parques y zonas destinadas al emplazamiento industrial se ha dado en torno a la ciudad capital, lo cual propició la emergencia de una zona metropolitana que tiene como núcleo la ciudad de Querétaro. ${ }^{1}$ Su ubicación, más las acciones y políticas emanadas desde el gobierno federal y estatal confluyeron para que importantes trasnacionales comenzaran a asentarse; a la par, comenzó una importante inmigración estimulada por la oferta de empleo, lo que derivó en un proceso de urbanización que contemplaba más espacios para la industria, la vivienda, los servicios y el comercio, y la consecuente dotación de infraestructura y servicios básicos.

Con el crecimiento de la ciudad, pueblos y ejidos aledaños pasaron a formar parte de la fisonomía urbana en poco tiempo; pero el proceso de urbanización incidió de diferentes maneras en los pueblos alcanzados; en algunos la identidad local se debilitó, junto con los rituales que otrora fueran signos de pertenencia; en otros se (re)construyó a partir de distintos referentes de identidad, como la memoria histórica (se conservan los lugares donde tuvieron lugar acontecimientos en el pasado), el patrimonio arquitectónico (edificaciones y monumentos y calles), fiestas y tradiciones, el ambiente (referido a las formas de vida social), la relación con el entorno natural (el territorio-signo) y la cosmovisión, así como en tantos otros más como los habitantes de esos lugares construyan para preservarse a sí mismos, para conservar su espacio y su identidad; en otras palabras, su sentido de pertenencia marcado por la territorialidad.

La expansión del área urbana se dio a expensas del suelo de uso agrícola y de los pueblos que se ubicaban en la cercanía de la ciudad. En el primer caso -la expansión a

I. Querétaro es el nombre del estado, el municipio y la ciudad capital, por ello es que se especifica la entidad territorial. 
La construcción de la pertenencia socioterritorial: el caso de Jurica, un pueblo al que le llegó la ciudad

expensas de tierras de uso agrícola-se distinguen dos tipos de propiedad que en buena medida incidieron en una urbanización diferenciada: el ejido y la propiedad privada. En cuanto a los primeros, lo que sucedió fue que en las tierras expropiadas por el gobierno, este construyó viviendas de interés social y zonas industriales, y en otros casos, los ejidos fueron 'invadidos' por sectores económicamente deprimidos y se edificaron colonias populares de autoconstrucción. En cuanto a la propiedad privada, fueron los fraccionadores (empresas privadas de muy diverso tamaño) los que construyeron vivienda para sectores medios y altos de la población (Icazuriaga y Osorio, 2007).

En el segundo caso -la expansión a expensas de los pueblos aledaños-, se debe señalar que hasta los años treinta era todavía reconocible el antiguo núcleo urbano de la ciudad de Querétaro, el cual contrastaba con nuevas zonas habitacionales que comenzaban a edificarse en terrenos de haciendas cercanas, y que con el proceso de urbanización varias de las haciendas prácticamente desaparecieron, aunque hubo otras cuyos núcleos poblacionales o caseríos no desaparecieron, sino que se conformaron como ranchos o pueblos adscritos a algún ejido. Con el tiempo, muchos de estos pueblos quedaron dentro de la ciudad. Este es el caso de Jurica. ${ }^{2}$

Como estudio de caso, Jurica resultó ser un buen ejemplo para dar cuenta de las diversas maneras como se relaciona el mundo agrario con el urbano-industrial. Los cambios más significativos en el territorio juriquense sucedieron en los años sesenta, cuando la entidad se estaba industrializando y se requirieron nuevas áreas para las industrias que estaban llegando y para los trabajadores. En este contexto comenzó la

2. Este proceso lo describe de igual manera Andrés Medina (2007), pero en una dimensión más amplia. El autor señala que el área urbana de la ciudad de México se constituía en un espacio particular que crecía rápidamente y arrasaba a su paso con los antiguos pueblos, asfixiando a la mayoría y deteniéndose frente a aquellos que defendían su integridad: como lo muestran actualmente los que componen los antiguos señoríos de Xochimilco, Tlalpan, Tláhuac y Milpa Alta. 
primera etapa de urbanización en Jurica, a través de la lotificación de los antiguos bordos de la hacienda. La expansión urbana sobre esta zona originó una creciente demanda de suelo urbanizable, por lo que comenzaron a venderse también las parcelas del ejido, y, de esta manera, poco a poco el pueblo fue perdiendo el control de buena parte de su territorio.

La urbanización generó la sensación de que Jurica se diluía-metafóricamente hablando- dando lugar a otra colonia periférica de la gran urbe, a un lugar que a la vista de cualquier observador externo podría fácilmente pasar por un asentamiento irregular -con viviendas de autoconstrucción, producto de la migración rural a la ciudad-y no por un pueblo con una historia añeja, propia y distinta a la de la ciudad. ${ }^{3}$

Pese a la urbanización y a los cambios que de ello se derivan, cuando los originarios hablan de Jurica hacen referencia a un pueblo con fronteras (reales y simbólicas), lo que permite distinguirlo de otros pueblos. Ellos expresan un sentimiento de pertenencia, por el hecho de que la gente de ahí se conoce entre sí, porque ahí nacieron y porque comparten códigos culturales. En ese contexto, me pregunté cómo es posible que en un espacio que se urbaniza aceleradamente se mantenga y se (re)construya la pertenencia, cómo se logra esto y para qué. Asumiendo que la pertenencia, como un atributo de la identidad, les permite no solo distinguirse de otros pueblos, sino de los "vecinos" que han llegado y siguen haciéndolo para quedarse, las respuestas a ambas interrogantes son las que desarrollo pormenorizadamente a lo largo de la tercera y última parte del presente artículo.

3. La historia de Jurica se remonta al siglo XVI, en diversos documentos históricos existen referencias a este lugar como estancia de ganado menor, propiedad de un cacique otomí, quien después la vendió a un español. A pesar de la referencia de población indígena, Jurica es un pueblo mestizo que no recupera ese pasado remoto. Para el siglo XVIII la referencia a Jurica es en torno a la hacienda del mismo nombre, una de las más importantes dentro del distrito de Querétaro; se habla también del caserío contiguo en donde vivían los trabajadores de la misma. 
La construcción de la pertenencia socioterritorial: el caso de Jurica, un pueblo al que le llegó la ciudad

Particularmente me intereso en el análisis de la relación territorio y cultura, ya que a partir de esta es posible distinguir los referentes que identifican a un lugar (un pueblo, un barrio, un vecindario) y lo diferencian de otro.

Respecto a la cultura, Giménez (2007) señala que esta tiene un papel preponderante en la vida humana, ya que funciona como mediadora entre los hombres y la naturaleza. De esta manera, todo fenómeno social tiene un referente en el espacio. En paralelo, todo grupo social tiene como referente primario un territorio. Es por ello que este adquiere una fuerza tal que la esencia de la identidad esta signada, en buena medida, por el lugar de origen. El territorio no se reduce a ser un mero escenario o 'contenedor' de los modos de producción y de la organización de los flujos de mercancías, capitales y personas, sino que también es un significante dentro de significados y un tupido entramado de relaciones simbólicas (Giménez, 2007). Tomo por sentado que el conocimiento que tienen las personas del espacio se encuentra trasminado por una diversidad de atributos propios (edad, trabajo, movilidad cotidiana, etcétera). De esta suerte, conocer y usar los espacios va de la mano con las prácticas, lo cual redunda en una apropiación territorial.

Lo relevante del estudio de la pertenencia es analizar lo que esta significa para las personas (Augé, 1995; Safa, 2001). Para ello identifiqué un espectro a partir del cual el espacio adquiere distintas connotaciones que sirven como referentes para el análisis. En primer lugar, consideré el espacio construido en cuanto al medio material, pero entendido desde la concepción de Rapoport (1978, p. 30), quien sostiene que "los elementos físicos de todas las ciudades son las mismas casas, las mismas calles y las mismas plazas, zonas de culto, etcétera. Es la naturaleza del significado de los principios subyacentes que los organizan y relacionan la que difiere". Considerar el espacio construido es importante porque nos habla de los sujetos que lo habitan. En segundo 
lugar, identifiqué el espacio practicado en términos de los usos, la apropiación y la interacción social, en tercer lugar incorporé el espacio imaginado, entendido como las imágenes y proyecciones que la gente hace de su pueblo (Silva, 2000), así como a la percepción sensible que se desarrolla por estar y vivir allí (Licona, 2007).

En este punto conviene aclarar que considero importante contemplar las relaciones identitarias que existen en los múltiples espacios (pueblos, barrios, vecindarios, colonias) que forman parte de la ciudad, ya que, parafraseando a Silva (2005, citado en Mujica), las identidades sociales, permiten a los ciudadanos ponerse de acuerdo en sus modos de ser y de estar en una colectividad, y estudiarlos es buscar comprender esas estrategias grupales para construirse en común. La mirada en lo local contribuye desde la academia a construir la ciudad que todos queremos y merecemos habitar.

Durante los años ochenta la antropología urbana mexicana comenzó a abordar las problemáticas de la ciudad desde un enfoque distinto al que se venía utilizando (más estructural) para incorporar una mirada fresca, una mirada centrada en los sujetos, las subjetividades y sus interacciones. De esta manera, la construcción de identidades en relación con el espacio urbano, es decir, las identidades vecinales, barriales, cargadas de significados que solo se le atribuían a los ámbitos más tradicionales y rurales, comenzó a ganar terreno en la investigación antropológica. Esta mirada se contraponía a los planteamientos de la individualización de los sujetos como elemento característico de las ciudades. A la homogeneidad como el destino irreversible de la humanidad se responde desde lo local y se observa que la tradición y sus espacios no solo no desaparecen, sino que se reconfiguran y se revitalizan (Hannerz, 1998; Castells, 2001; Portal y Safa, 2005; García Canclini, 2005).

Dicho esto, el presente articulo se divide en tres apartados, en el primero presento el encuadre teórico metodológico 
La construcción de la pertenencia socioterritorial: el caso de Jurica, un pueblo al que le llegó la ciudad

a partir de la cual construí el objeto de estudio. En seguida describo brevemente los cambios más importantes que han marcado el devenir histórico del pueblo de Jurica. Después, presento el análisis del espacio y la (re)construcción de la pertenencia.

\section{El encuadre teórico metodológico}

En el caso de los pueblos que han quedado dentro de la ciudad, la cultura y la identidad son elementos sustanciales que permiten distinguirlos de otros espacios locales. ${ }^{4}$ Gilberto Giménez (2007) establece la existencia de tres dimensiones desde donde es posible relacionar la cultura y el territorio. En la primera, el territorio constituye por sí mismo un espacio de inscripción de la cultura y, por lo tanto, equivale a una de sus formas de objetivación. El autor se refiere a que la mayoría de los territorios están 'tatuados' por las huellas de la historia, de la cultura y del trabajo humano. Esta es la perspectiva que asume la llamada geografía cultural, la cual introduce, entre otros, el concepto clave de geosímbolo. Bonnemaison (1981, citado en Giménez, 2007, p. 125) define a este como "un lugar, un itinerario, una extensión o un accidente geográfico que por razones políticas, religiosas o culturales revisten a los ojos de ciertos pueblos o grupos sociales una dimensión simbólica que alimenta y conforta su identidad". Desde este punto de vista, Giménez (2007) sintetiza los referentes geosimbólicos como territorio-signo.

En la segunda dimensión, el territorio puede servir como un área de distribución de instituciones y prácticas cultura-

4. Por espacios locales me refiero -bajo el amparo del planteamiento de Portal (1999)- a los pueblos, vecindarios y barrios que están en la ciudad; espacios en donde sus habitantes (re)construyen su pertenencia a partir de lo que nombraron los antepasados, de lo que se recuerda colectivamente, de sus códigos culturales -valores, creencias y prácticas- y de la delimitación de sus fronteras, ya sean físicas, simbólicas o ambas. 
les espacialmente localizadas, aunque no intrínsecamente ligadas a un determinado espacio, como en el caso precedente. Se trata siempre de rasgos culturales objetivados, como las pautas distintivas de comportamiento, las vestimentas peculiares, las fiestas del ciclo anual, los rituales específicos que acompañan al ciclo de la vida, entre otros. El conjunto de estos rasgos son lo que se puede denominar cultura etnográfica (Bouchard, 1994, citado en Giménez, 2007).

En la tercera, el territorio puede ser apropiado subjetivamente como objeto de representación y de apego afectivo y, por ende, como símbolo de pertenencia socioterritorial. En este caso los sujetos (individuales o colectivos) interiorizan el espacio integrándolo a su propio sistema cultural. Con esto, se pasa de una realidad territorial "externa" culturalmente marcada a una realidad territorial "interna" e invisible, resultante de la "filtración" subjetiva de la primera, con la cual coexiste. Partiendo de esta premisa, se puede abandonar físicamente un territorio, sin perder la referencia simbólica y subjetiva al mismo a través de la comunicación a distancia, la memoria, el recuerdo y la nostalgia (Giménez, 2007).

El "territorio" se ha vuelto una palabra común en el diálogo entre los científicos sociales. La definición del concepto no es única, aunque se comparte generalmente la noción de un espacio apropiado mítica, social, política o materialmente por un grupo social que se "distingue" de sus vecinos por prácticas espaciales propias (Bonnemaison, 1986, citado en Hoffmann y Salmerón, 1997, p. 23). ${ }^{5}$

\footnotetext{
5. Existe una vasta bibliografía que da cuenta de las diferencias conceptuales entre territorio y espacio. Sin embargo, en el caso que me ocupa, entrar en esta revisión es desviar el tema de atención dado que no es una discusión central.Asumo que cuando se habla de territorio predomina una perspectiva material (como entorno físico), mientras que cuando se habla de espacio, la referencia implica concepciones no solo materiales, sino culturales y simbólicas. Desde esta premisa concibo el espacio como un territorio apropiado, construido a través de la acción y las representaciones sociales.
} 
La construcción de la pertenencia socioterritorial: el caso de Jurica, un pueblo al que le llegó la ciudad

Las personas construyen referencias de pertenencia por ser el lugar donde nacieron o por ser el lugar donde crecieron. Ambas implican formas distintas de relacionarse con el territorio. Metodológicamente es importante estudiar cómo en Jurica los distintos grupos usan, construyen y viven un territorio que comparten. Para poder conocer y acceder a los procesos y las formas en que la gente construye su pertenencia realicé trabajo etnográfico, ya que de esta manera podía observar los contextos espaciales y temporales constitutivos de la acción y la interacción. Además, la etnografía me permitió establecer nexos y una relación cercana, cara a cara, con los entrevistados. ${ }^{6}$

La primera elección metodológica que consideré fue el estudio de la pertenencia socioterritorial como una identidad signada por rasgos físicos-culturales (Pollini, 2000, citado en Flores y Salles, 2001), como una construcción social y cultural de prácticas y representaciones que llevan a generar distintos niveles de involucramiento con el territorio. La segunda estrategia fue articular las diferentes dimensiones que intervienen en la construcción social del espacio y como estas se significan de manera distinta entre los grupos (los originarios y los no originarios), así como diferencias generacionales. ${ }^{7}$

En Jurica, como señalaron algunos entrevistados que ahí trabajan (directores de planteles, maestros, doctores) se conjunta lo tradicional de los pueblos -el alcohol, el machismo- y lo marginal de las ciudades -una periferia empobrecida, con poca escolaridad y empleo informal-, esta es la percepción que la mayor parte de la gente de fuera tiene

6. Ademas de la etnografía apliqué un formulario-encuesta compuesto por un apartado de categorías fijas y dos apartados más sobre evocaciones y usos del espacio. La aplicación del formulario fue más de orden indagatorio y cualitativo que probabilístico.

7. En el tercer recorte metodológico distingo tres grupos generacionales:jóvenes (de doce a veintinueve años), adultos (entre treinta y cincuenta y nueve) y mayores (sesenta años y más).

Sociedad No. 62 
del pueblo. Sin embargo, la gente del pueblo, la que toda su vida ha vivido ahí, habla de sus costumbres y tradiciones, de la fiesta patronal, del trabajo, de su vida en la hacienda y de la importancia que para ellos tenía el río, de las veces que siendo niños nadaron en las aguas cristalinas, desnudos y sin pena, porque "no había malos pensamientos, ni malas cosas, como ahora" (ejidatario, 89 años); en fin, de un lugar que a simple vista yo no observaba.

Estas visiones polarizadas fueron las que en principio me llevaron a indagar sobre este pueblo como un lugar imaginado (desde la perspectiva de Anderson), que se construye a partir de un sentido de pertenencia porque significa algo para la gente de este lugar. Conforme avancé en el trabajo de campo mi perspectiva se fue afinando y decidí que mi punto de partida, la perspectiva desde la cual iba a investigar, sería la de los juriquenses; una decisión en la cual fueron determinantes los recorridos y los primeros contactos que tuve con la gente del lugar.

\section{La construcción histórica del pueblo}

Jurica es un pueblo donde la agricultura -ligada a la hacienda del mismo nombre- fue la principal actividad económica, pero donde el proceso de urbanización transformó los espacios y las actividades, por lo que sus habitantes tuvieron que dedicarse al comercio y a los servicios, es decir, tuvieron que incorporarse a la economía capitalista, al punto que hoy mantienen una relación cotidiana y directa con la economía y la cultura urbana.

Los acontecimientos que han trasformado el territorio y la vida de los juriquenses se pueden clasificar en cambios de orden interno y de orden externo. Es por eso que los dividí para fines analíticos, aunque se trate de cambios que en la realidad han estado estrechamente relacionados. 
La construcción de la pertenencia socioterritorial: el caso de Jurica, un pueblo al que le llegó la ciudad

En el orden interno, los más importantes se vinculan con el reparto agrario llevado a cabo a finales de los años treinta, y con la desestructuración de la hacienda de Jurica, ocurrida por su venta en los años sesenta. Con el reparto agrario no todos los jefes de familia en Jurica fueron beneficiados - los que se quedaron sin tierra siguieron trabajando en la hacienda, mientras que los nuevos ejidatarios comenzaron a trabajar sus parcelas-, lo que sucedió fue que a pesar de la resolución presidencial sobre la dotación de tierras en Jurica (1939), el hacendado Carlos Urquiza no entregó más de 400 hectáreas supuestamente propiedad del ejido. El litigio fue largo, todavía a mediados de los años sesenta había quejas por incumplimiento y los ejidatarios seguían solicitando que se les restituyera la superficie ejidal total o que se hiciera una ampliación, pero no sucedió ni una cosa ni la otra. ${ }^{8}$ En 1960 Carlos Urquiza vendió la hacienda y con esto prácticamente se ‘diluyó' el conflicto. La hacienda se convirtió en hotel y las hectáreas que habían sido sembradíos, llamadas por los lugareños "los bordos" (las reclamadas por los ejidatarios), se lotificaron rápidamente para convertirse en un fraccionamiento campestre. La desestructuración de la hacienda llevó a varias personas a emigrar a la ciudad en busca de trabajo, y a otras tantas a buscar trabajo en el hotel, como jardineros, botones, recamaristas, etc., o bien en el fraccionamiento campestre, como empleadas domésticas, jardineros y mozos.

El segundo orden (el externo) se relaciona con el proceso de industrialización ocurrido a mediados de los años sesenta. La llegada de importantes trasnacionales requería espacio no solo para la industria, sino también para la vivienda. De esta manera se comenzó a atender la demanda creciente de diferentes estratos de trabajadores (en el caso del fraccio-

8. Archivo del Registro Agrario Nacional (RAN), delegación Querétaro, cajas 165, 563,564 y 565 .

Sociedad No. 62 
namiento Jurica Campestre se pensó en residencias para los mandos medios y gerenciales). Inició así una importante oleada de inmigrantes. Jurica se convirtió en receptáculo de parte de las corrientes migratorias que llegaban a la ciudad; en buena medida por los costos menores del suelo y la vivienda, y por la cercanía con los lugares de trabajo (el hotel y zona industrial, principalmente). La expansión urbana sobre esta zona de la ciudad originó una creciente demanda de suelo urbanizable, por lo cual comenzaron a venderse también las parcelas del ejido, y así, poco a poco, el pueblo fue perdiendo el control de parte de su territorio. Otro acontecimiento que influyó en este orden fue el sismo de 1985; siniestro que intensificó la llegada de nuevos residentes provenientes principalmente de la ciudad de México.

La demanda de tierra para uso habitacional ha sido uno de los elementos que más ha impactado en el cambio de uso de suelo en Jurica. Sin embargo, conforme esta ha aumentado, la población originaria se ha arraigado más en su terruño. Esto quedó manifiesto durante el trabajo de campo, ya que en reiteradas ocasiones los juriquenses señalaron que aunque pudieran irse de ahí, no lo harían. A pesar de que los solares se han dividido y por ende, los predios se han achicado, siguen siendo amplios si se les compara con las viviendas a las que pueden tener acceso en la ciudad. Es por ello que muchos de los trabajadores, aunque tengan derecho a un crédito para vivienda (Infonavit o Fovissste) prefieren construir en Jurica, ya que les gusta más el entorno, el "verdor" y, principalmente, estar cerca de su familia.

Los límites territoriales, los mapas y las imágenes espaciales que la gente recuerda es lo que conforma, por una parte, la memoria del espacio vivido y por la otra, lo que contribuye a la reproducción de la memoria colectiva y al uso social del espacio, un uso que, como apunta Silva (2000), permite ubicar a los usuarios "familiarizados", los que se 
La construcción de la pertenencia socioterritorial: el caso de Jurica, un pueblo al que le llegó la ciudad

autorreconocen y los que pertenecen al lugar. Las personas mayores recuerdan claramente la estructura del pueblo, los límites de cada solar y a quién le pertenencia; también son capaces de dar cuenta del fraccionamiento de los solares, cuáles se fueron heredando, qué áreas se utilizaron para el beneficio colectivo (construcción de escuela, parroquia, jardín, etc.), cuáles se expropiaron y cuáles se vendieron. De esta forma la reconstrucción del pasado en el presente se constituye como parte de la identidad del pueblo en la actualidad.

\section{La construcción social del espacio: prácticas y usos,} pertenencia y arraigo

\section{I El espacio construido}

La urbanización del pueblo llevó a perfilar tres zonas claramente diferenciadas por su historicidad y su poblamiento: la primera es el centro (que a su vez se subdivide en lo que la gente llama "los de arriba" y "los de abajo"). El centro es la parte más antigua del pueblo, fue el primer asentamiento poblacional. Jurica era un pequeño caserío en donde vivían los trabajadores que laboraban en la hacienda del mismo nombre. La segunda zona en orden de aparición fue Gobernantes, la cual comenzó a poblarse hace treinta años. La mayoría de sus residentes son los descendientes de los mismos juriquenses y, en menor número, gente de otros lugares que ha llegado a vivir ahí. La tercera y última es La Campana; un asentamiento que comenzó a poblarse hace quince años, cuyos residentes son básicamente gente de fuera (véase Mapa 1).

Las calles más antiguas son los callejones o calles estrechas, la cuales, a diferencia de las más recientes (de traza urbana, reticulares y anchas), son serpenteantes (de tierra y empedrado). Las viviendas más antiguas se ubican en el centro, particularmente en la zona aledaña a la Capilla, o 
lo que la gente denomina el barrio de la Capilla. Se trata de grandes solares en donde viven las familias originarias y sus descendientes. Les siguen las construcciones más nuevas, viviendas unifamiliares (pero de autoconstrucción, en Gobernantes y La Campana), que se distinguen de los conjuntos cerrados residenciales construidos en las inmediaciones o en las antiguas parcelas de lo que otrora fue parte del ejido.

Durante las entrevistas, la gente identificó el cambio más importante a partir de la lotificación de los "bordos". Con ello se dio el cambio de uso de suelo más intensivo del que la gente tiene memoria. Las tierras de regadío de la hacienda, donde trabajaron muchos, desaparecieron rápidamente para dar origen al fraccionamiento residencial Jurica Campestre. ${ }^{9}$ Debido al rápido crecimiento urbano, en 1990 Jurica se integró a la ciudad de Querétaro y se dividió en dos AGEB (véase Mapa 1). ${ }^{10}$

Durante los años setenta y ochenta comenzaron a venderse tierras de uso común o agostadero, así como lotes dentro del fundo legal. La venta de terrenos respondió a la demanda creciente del mercado; el problema fue que los lotes no contaban con ningún tipo de servicio ni infraestructura. Para regularizar el asentamiento humano, así como la venta de terrenos en el fundo legal, la Comisión para la Regularización de la Tenencia de la Tierra (Corett) llevó a cabo dos expropiaciones: la primera en 1992, con un total de 70.37 hectáreas, y la segunda en 1995, afectando 3.65 hectáreas. El decreto de expropiación autorizó a Corett a vender los terrenos en lotes, tanto a avecindados que constituían el asentamiento humano irregular como a terceros. En el terreno práctico, más que vender, Corett legalizó y

9. Para 1970 el fraccionamiento tenía una superficie de 2612674 ms2 (2 272584 de superficie lotificada y $340090 \mathrm{mt} 2$ para calles). Dos años después se autorizó a Jurica Fraccionamiento Campestre S.A. iniciar la venta de lotes (hoja 336/654, RAN). 10. Hasta 1980 se había considerado como localidad, es decir, zona rural. 
Mapa 1. División territorial del pueblo de Jurica

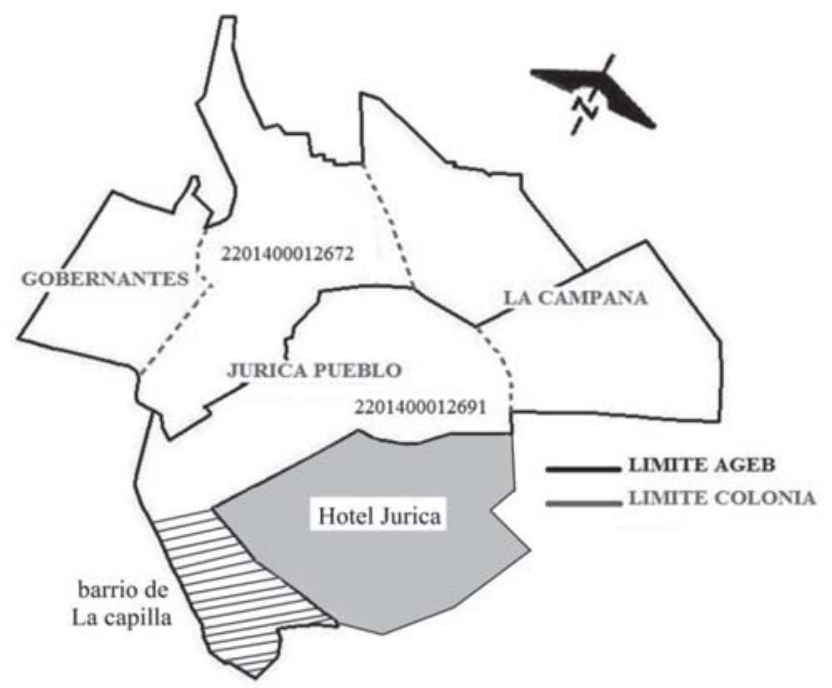

Fuente: elaboración propia con base en INEGI, 2010.

regularizó un proceso que ya se había venido dando desde tiempo atrás.

Para los juriquenses, el crecimiento implicó una urbanización "forzada", ya que no estuvo acompañada de la dotación de servicios básicos ni de la infraestructura mínima requerida. En este contexto el pueblo creció sin planeación, sin regulación y expuesto a la constante presión del capital inmobiliario, lo cual ha originado que en muchos casos, las familias vivan en condiciones de precariedad y vulnerabilidad. De antemano se sabe que la urbanización trae consigo problemas consustanciales graves, pero también se sabe que en las manos de los gobiernos está resolverlos, atenuarlos o aminorarlos, compensando de alguna manera a las poblaciones que, por efectos del "desarrollo", han visto mermada su calidad de vida. En Jurica se pueden citar varios ejemplos que ilustran claramente la falta de atención 
u omisión, puesto que se ha pasado por alto la contaminación del río, sin mencionar la afectación de otras zonas del pueblo. En el caso del barrio de la Capilla, la zona más baja donde confluyen todas las aguas que descienden, el dren se desborda porque no tiene la capacidad de retener la cantidad de agua de una población que crece constantemente. La deforestación ha sido otro elemento consustancial al crecimiento que ha minado severamente la filtración del agua al subsuelo; situación que ha provocado cambios en el paisaje y en las prácticas cotidianas que realizaba la gente del lugar (recolección -de nopales, pitayas, tunas, etc.- y "leña", principalmente).

\subsection{El espacio practicado}

El espacio practicado o espacio vivido es un territorio marcado por la cultura, un espacio en donde la gente comparte una historia común, un lugar con fronteras (físicas o simbólicas), un lugar que tiene una identidad propia por sus atributos naturales (referentes geosimbólicos) y culturales (tradiciones y costumbres).

En el centro del pueblo vive la mayor parte de las familias más antiguas y de las personas mayores. Su práctica del espacio hace referencia a recuerdos elaborados en un pasado remoto, más que inmediato, se refieren a las transformaciones del espacio natural, los edificios según el uso que tuvieron, a las construcciones que sustituyeron otros espacios o los cambios sucedidos en los espacios públicos. Como señala Alfredo Guerrero (2007) los viejos residentes son usuarios legítimos de las calles, de los espacios públicos, de los comercios. En ellos hay una visión del espacio fuertemente anclada en el pasado, mientras que para los más jóvenes la práctica del espacio se constriñe en función de la experiencia cotidiana regida por la inmediatez. En Jurica, el utilitarismo del espacio se observa de manera más clara en los "fuereños", para quienes Jurica es solo un dormito- 
La construcción de la pertenencia socioterritorial: el caso de Jurica, un pueblo al que le llegó la ciudad

rio: trabajan y viven en la ciudad, más que en el pueblo, no hacen uso de los espacios públicos ni se involucran en la vida cotidiana que acontece en el lugar.

Uno de los efectos de la lotificación del pueblo es que la gente ha tenido que cambiar sus recorridos: espacios por los que antes atravesaban fueron cerrados o trasformados (se construyeron edificaciones públicas y viviendas, se trazaron calles). Los recorridos van ahora por caminos oficiales. La gente del pueblo conoce todos los atajos que existen, los mapas espaciales que construyeron suelen utilizarlos en la medida en que les es posible. Ellos acostumbran "recortar" su trayecto por diferentes pasos; de modo que se puede decir que a través de los recorridos la gente transmite una memoria de los lugares y que estos, a su vez, cumplen con una función pedagógica. En ese sentido, como sostiene De Certeau (2007), la práctica de caminar por el pueblo es desde la infancia una técnica de reconocimiento del espacio en calidad de espacio social. Los atajos, por otra parte, no solo permiten acortar la distancia de los recorridos, también sirven para evitar pasar por lugares que se consideran desagradables o peligrosos (Silva, 2000).

Cuando la gente es capaz de nombrar diferencias -físicas o culturales- del lugar donde ha nacido y crecido o donde únicamente reside se puede asumir que hay sentimiento de arraigo, lo que incide en la construcción de la identidad local (Flores y Salles, 2001). Bajo esta premisa, pregunté a mis entrevistados qué hace diferente a Jurica de otros lugares. La mayoría de ellos consideró que lo que lo distingue es su gente, sus tradiciones y sus costumbres (el Santo Patrono y su fiesta patronal). Otros elementos mencionados fueron el entorno natural (paisaje y medio ambiente) y la contribución de estos en hacer de Jurica un pueblo "bonito", "grande", "tranquilo", "chido".

Los rasgos que permiten considerar a Jurica un pueblo son diferentes para cada grupo generacional. Esta pregunta 
es importante porque la identidad social se construye por pertenencia, por referencia (a ideas y valores) y por contraste (por distinción u oposición a otros) (De la Peña y De la Torre, 1994). Así pues, las personas mayores significan así el pueblo: en comparación a lo que era antes. Para ellos Jurica dejó de ser un rancho con callejones, organales, calles de tierra y casas de adobe, para convertirse en un pueblo que hoy tiene mejores servicios e infraestructura, es decir, se urbanizó.

Los adultos lo significan también como pueblo, pero por la comparación que establecen con la ciudad. Consideran a Jurica un pueblo por la poca urbanización y el modo de vida tradicional (costumbres y trabajo en la milpa). Por su parte, los jóvenes lo consideran un pueblo por sus características materiales (es pequeño, le falta urbanización, etcétera); para otro sector de la juventud es un lugar que se está convirtiendo en una colonia, es decir, está cambiando debido a que continuamente llega gente de fuera. En las respuestas de los jóvenes se destaca la estructura material, mientras que los elementos culturales -que son los que más fácilmente pueden distinguir a un pueblo- prácticamente pasan inadvertidos, a diferencia de las respuestas de los otros dos grupos.

Finalmente, en cuanto al espacio practicado, las procesiones, como las tradiciones -entre ellas la fiesta patronal-, son invenciones ${ }^{11}$ que tienen un uso social importante. El espacio original en donde se celebra la fiesta ha sido siempre la Capilla. ${ }^{12}$ Es el lugar de la morada del Santo Patrono,

II. La tradición inventada para Hobsbawm (1992) es un grupo de prácticas, normalmente gobernadas por reglas aceptadas, abierta o tácitamente, y de naturaleza simbólica o ritual, que buscan inculcar determinados valores o normas de comportamiento por medio de la repetición, lo cual implica automáticamente continuidad con el pasado real o inventado.

12. En 1999 el INAH realizó un registro (catálogo) de monumentos históricos (inmuebles).Tres de ellos se ubican en Jurica: La Capilla y la hacienda están fechadas en el siglo XVI, y la huerta en el siglo XVIII. La Capilla del Señor de la Piedad consta de atrio, dos calvaritos, Capilla y sacristía, se pavimentó en 1938, se le puso una nave agregada a la izquierda y una cúpula en 1982. 
La construcción de la pertenencia socioterritorial: el caso de Jurica, un pueblo al que le llegó la ciudad

en este sentido, los rituales consagran este espacio. Como señala Mircea Eliade (1983) hay espacios sagrados y por tanto, fuertes, significativos, y hay otros espacios no consagrados, sin estructura ni consistencia. Sostiene que la experiencia religiosa de la no-homogeneidad del espacio constituye una experiencia primordial, equiparable a una "fundación del mundo". Se trata de una experiencia religiosa primaria, anterior a toda reflexión sobre el mundo; es la ruptura operada en el espacio lo que permite la constitución del mundo, el eje central de toda orientación futura, un punto fijo absoluto, un "centro". Durante los días de fiesta, la Capilla vuelve a ser el centro y el origen del pueblo, la zona más antigua y donde se asentaron las familias originarias.

Hasta hace pocos años, las procesiones en Jurica ${ }^{13}$ se realizaban dentro de un espacio claramente delimitado que se circunscribía a la zona centro, particularmente en torno a la Capilla, a través de este ritual se refrendaba la identidad local vinculada al espacio sagrado y se objetivaba el sentido de pertenencia, que distingue a los originarios de los que no lo son. En este sentido, las procesiones marcaban claramente las diferencias. Sin embargo, en fechas recientes, a través de la intermediación de los sacerdotes, el espacio local, ese espacio originario, se ha ido ampliando y los recorridos hoy se hacen a zonas que anteriormente no eran visitadas por el Santo Patrono. Para la gente que llegó de fuera (inmigrantes que tienen más de sesenta años viviendo en el pueblo) y para el sacerdote este cambio ha sido favorable, porque, desde su óptica, se busca integrar a la comunidad en su conjunto. Sin embargo, a los ojos de la gente de la Capilla estas acciones más bien se han encaminado a desplazarlos. En este caso, la identidad se

I3. Durante el año de trabajo de campo presencié un total de veintiuna procesiones en el pueblo, la mayoría se realizaron durante los dos últimos meses del año, en el marco de la celebración de la fiesta patronal, la cual tiene lugar del 24 al 27 de diciembre.

Sociedad No. 62 
construye a partir de la distinción entre nosotros (los originarios) frente a los otros (los fuereños), entre la autoridad tradicional (sistema de cargos) y la autoridad eclesiástica (sacerdotes), relaciones que implican una constante y permanente tensión, negociación o resistencia.

\subsection{Fronteras fisicas y simbólicas}

La fenomenología ha venido a complejizar y enriquecer la interpretación de los territorios como sistemas de símbolos, ya que sirve de fundamento para determinar linderos y fronteras, cuando estos han sido históricamente alterados pero conservados en la memoria colectiva y el uso ritual, como ha sido en Jurica. El crecimiento del pueblo ha ido ampliando las fronteras espaciales:

Apenas llegaba aquí adelantito del campo donde hay un señor Felipe Loyola y unos Breñas [...] adelantito de donde venden las carnitas. Esa era la última casa y luego donde está la huerta, una cuadra más adelante, era la última casa. Yo tenía como doce años y La Campana y Gobernantes era puro agostadero, pero ya después fueron vendiendo y de ahí se ha seguido (Juan Guerrero Sánchez, setenta años).

Del testimonio anterior destaca lo que Silva (2000) llama las marcas del territorio. Sostiene que las fronteras tienen una acepción indicativa como cultural. El uso social de un espacio marca los bordes dentro de los cuales los usuarios "familiarizados" se autoreconocen, y fuera de los cuales se ubica a los extranjeros, a los que no pertenece al territorio (p. 53).

En Jurica la gente recuerda muy bien hasta dónde llegaba el pueblo; identifican como las fronteras se han ido recorriendo conforme ha avanzado el proceso de urbanización; también identifica temporalmente cuáles han sido los cambios. Las personas son capaces de reconocer desde donde comienza el pueblo (las entradas) y hasta donde llega. 
La construcción de la pertenencia socioterritorial: el caso de Jurica, un pueblo al que le llegó la ciudad

Señalan que las fronteras del pueblo son los espacios que más han cambiado (los límites del pueblo con el fraccionamiento y con la carretera 57); en contraposición, la zona del centro es la que menos cambios físicos ha tenido; hasta cierto punto, se ha poblado porque los solares se dividieron pero los habitantes son descendientes de las familias antiguas. La mayor parte de la gente que vive en el centro son los usuarios de las calles, los espacios públicos, los comercios, de todo lo que hay en Jurica. En este sentido, la gente no sólo se identifica con su pueblo, sino que lo mantiene vivo porque lo habita y lo usa.

\subsubsection{Referentes geosimbólicos}

Para la gente del pueblo, el entorno natural, la vegetación y el "verdor" de Jurica son elementos que los distinguen. ${ }^{14}$ Las personas mayores recuerdan que Jurica era un lugar con bastante agua. Entre los lugares que identificaban a su pueblo mencionaron El Salto (presa), el cerro de las palomas, los bordos, la mezquitada, por la que tenían que atravesar para ir a El Nabo (comunidad vecina). Algunos de estos lugares hoy solo quedan en el recuerdo. El entorno natural también constituía un importante espacio para pasar el tiempo libre, pero con la urbanización no solo los lugares, sino también algunas prácticas asociadas a ellos, han ido desapareciendo:

Antes usted iba al campo y jallaba [sic] garambullitos, tunitas, pitayitas. Cada año resucitaba aquella planta que nos estaba dando vida, pero ahora han comprado y los han tirado y 'ora voy a ver si jallo [sic] un nopalito, una tunita, pero ya casi no [...]. Me gustaba mucho correr y agarraba puro cerro, y no que ahora pura calle (Porfirio Cruz Benítez, ochenta y cinco años).

14. De acuerdo a la tradición oral, Jurica significa en otomí 'lugar de salud', característica que se le atribuía por la abundancia de agua. 
Cabe resaltar que son solamente las personas mayores las que hablan del entorno natural con empatía y respeto. Hablan de una planta o un de un árbol en los términos con los que se referirían a un ser vivo y que siente:

Luego andan los chamacos tumbándole los brazos a los pitayos. Yo me acuerdo que nosotros hacíamos unas rejitas para quitar las pitayas y no molestarlos, pero 'ora las tumban a piedrazos o para bajar la fruta les arrancan los brazos. Yo les digo que las plantas también sienten: "a ver, ¿qué sentirías si te cortara un brazo?, ¿te iba a doler, verdá? Pus [sic] a ellas también les duele"; pero ni caso hacen (Florencio Moreno Villanueva, sesenta y ocho años).

El respeto por el medio natural, sobre todo cuando se trata de árboles muy antiguos, ayuda a comprender por qué en las calles del centro es posible ver árboles a la mitad de una banqueta o que atraviesen el muro de una casa hacia la calle; un panorama que ya no se ven en zonas más nuevas como La Campana, donde los mismos juriquenses han sido testigos de la deforestación indiscriminada en aras de la urbanización.

\subsection{Espacio imaginado}

La evocación de un lugar emerge cuando la gente es capaz de manifestar lo que valoran de él a través de los atributos que le reconocen (lo que los identifica): los lugares que sirven de marco a la memoria, que son recordados individual y colectivamente, que significan algo para la gente que habita en ellos (Silva, 2000; Safa, 2001).

Desde esta premisa pregunté por los lugares más bellos de Jurica. Y en orden de importancia, por el número de menciones que se hicieron de ellos, están la plaza, la parroquia, la Capilla, la hacienda, el cerro, las canchas, el hotel, el Regency, la Crucita, el río y el bordo. Estos lugares se pueden agrupar en espacios de recreación y esparcimiento, 
La construcción de la pertenencia socioterritorial: el caso de Jurica, un pueblo al que le llegó la ciudad

históricos, religiosos, naturales; aunque también se hace referencia a los mejor urbanizados (Regency, el fraccionamiento residencial y Paseo del Mesón). En las respuestas aparecieron significados asociados a los espacios nombrados. Por ejemplo, de la plaza se subrayó no solo la relevancia que tiene en la vida cotidiana para la gente del pueblo como centro de reunión por excelencia, también se destacaron sus atributos físicos, ya que se la considera un lugar limpio y pintado, con aéreas verdes; características que hacen más placentera la estancia.

Las respuestas nos conducen a señalar que la belleza de los lugares está asociada a otros campos semánticos. Los espacios son bellos por ser históricos, recreativos, limpios, de recogimiento (paz), además se valora lo bello a partir del entorno natural: por el verdor, la vegetación, los paisajes y la tranquilidad que se puede experimentar en esos lugares.

Otro de los aspectos referentes a la percepción se refiere al color. En este sentido, Silva (2000) sostiene que el color no es sólo un problema del arte sino de la vida cotidiana. De la misma manera, Licona (2007) señala que estudiosos del diseño, la psicología y la arquitectura apuntan que el lenguaje de los colores habla. Cada color es un signo que posee su propio significado. Por ejemplo los psicólogos se refieren a las diferentes impresiones que emanan del ambiente creado por el color; impresiones que pueden ser de calma, de recogimiento, de alegría, violencia, etcétera.

Desde la premisa de que el color es un lenguaje que refiere elementos de la vida cotidiana pregunte cuál consideraban ser el color representativo de Jurica y por qué. Se mencionaron quince colores. Las personas mayores y los adultos mencionaron en primer lugar el verde, el blanco (por la paz y la pureza) y el azul (por el cielo claro). Estas respuestas me parecieron congruentes, porque para una persona que viene de "fuera", como es mi caso, el color representativo es el verde por la cantidad y diversidad de árboles y flores que 
hay en este lugar. Sin embargo, la respuesta de los jóvenes fue en otro sentido; el color que significa a Jurica es el rojo (por el Señor de la Piedad -el Santo Patrono-, porque hay amor, son solidarios), el negro o azul obscuro (por los problemas sociales: drogadicción, alcoholismo, vandalismo) y, hasta el tercer lugar, el verde.

Finalmente, ante la pregunta proyectiva ¿cómo les gustaría que fuera Jurica? (espacio ideal), respondieron "más bonito", "tranquilo" y "más unido". Los juriquenses se refieren a "más bonito" en términos de mejoramiento en la calidad de vida (infraestructura, servicios y educación) y educación cívica (cuidar el medio ambiente, no tirar basura, más 'civilizados'), "más tranquilo" en términos de la reducción de delitos y conflictos asociados al alcoholismo y la drogadicción, para lo cual es necesario, en su opinión, mayor comunicación entre padres e hijos y más vigilancia por parte de las autoridades; por último, con "más unido" se refieren a las divisiones internas (entre los de "arriba" y los de "abajo", y debido a los conflictos familiares por las tierras).

\section{Consideraciones finales}

Las investigaciones sobre los pueblos en la ciudad se encuentran concentradas geográficamente en dos de las áreas urbanas más grandes del país, el Distrito Federal y Guadalajara. Asumo que justamente por el tamaño de estas ciudades, el fenómeno de la incorporación de los pueblos aledaños es un tema que se deriva del crecimiento urbano y por ello se privilegia su estudio. Sin embargo, en ciudades medias, como Querétaro, este fenómeno no es ajeno, y por ello la necesidad y el interés por explorarlo.

Con el proceso de urbanización se han dado transformaciones que se reflejan en diferentes escalas, formas de vida, formas de organizar y significar el territorio. En síntesis: 
La construcción de la pertenencia socioterritorial: el caso de Jurica, un pueblo al que le llegó la ciudad

diferentes formas de pertenecer. En este sentido, me parece que es necesario seguir investigando y profundizar sobre los espacios, lugares, tradiciones, celebraciones y acciones que nos permiten conocer quiénes son los habitantes de esos pueblos que han quedado dentro de la ciudad. En el marco general de la antropología urbana mexicana esta investigación se suma a otras más que estudian los significados que los habitantes construyen sobre el espacio urbano y que son fundamentales para comprender la pertenencia, las formas de usar y habitar el espacio, así como la construcción de la identidad local.

Es importante que se estudien los pueblos no solo por las costumbres y tradiciones que se reproducen como parte de la cultura local, sino porque la construcción de la pertenencia per se constituye una determinación sociológica y antropológica de suma relevancia. Desde finales de los años sesenta planteaba Ledrut (1968, p. 26-7) que las colectividades territoriales, cualesquiera que fuesen, no eran simples agregados de población y advertía: que "[...] si no se quiere llegar a una mutilación sistemática de la realidad urbana, es indispensable estudiar los mecanismos y procesos de estructuración colectiva del espacio, al igual que los tipos de organización del espacio social. Toda unidad posee un alma y una personalidad, aun si carece de voluntad o razón”.

Hoy por hoy la organización social del espacio sigue siendo una asignatura pendiente dentro de la planificación. Con frecuencia la planificación es algo indeterminado en el espacio y, en general, los planes de urbanismo siguen sin relacionarse con criterios positivos de futuro. Un elemento central que al respecto subraya Ledrut (1968) es que las funciones urbanas deben llenar las necesidades colectivas; algo que no es común en los planes de gobierno. El autor sostiene que una ciudad puede satisfacer a cada uno de sus habitantes únicamente a través de una finalidad colectiva, rescatando los aspectos colectivos del urbanismo. Las 
necesidades colectivas deben aprenderse observando a los individuos, su comportamiento, sus actitudes e, incluso, la expresión de sus insatisfacciones. Pareciera que ha transcurrido mucho tiempo desde que Ledrut hizo estos planteamientos, y que algo se hizo por resolver los problemas que ya estaban siendo detectados en otros lugares, pero no ha sido así.

En Querétaro cada sexenio se presenta un Plan de Desarrollo a partir del cual se proyecta la aplicación de políticas que impacten directamente sobre el espacio y sus habitantes. En esa aplicación poco cuidado se ha tenido al considerar la organización social del espacio como un fenómeno colectivo natural de ciertos lugares (pueblos como el de Jurica, por ejemplo) que cotidianamente son invadidos por la ciudad.

En Jurica la urbanización implica cambios que no solo atañen al territorio: la gente atribuye a este proceso la llegada creciente de inmigrantes y el surgimiento de problemas que antes no tenían. El crecimiento poblacional y la progresiva demanda de vivienda sin una planeación adecuada ha dado como resultado que se agudicen los problemas en cuanto a servicios básicos e infraestructura que ya se padecían. En este crecimiento no se han considerado tampoco los efectos de deterioro del medio ambiente. La degradación de los espacios naturales que otrora fueran espacios importantes de socialización ha dado lugar a que la gente se haya ido replegando al espacio del hogar, lo cual, a la larga, empobrece la calidad de vida. ${ }^{15}$

Los cambios derivados de la urbanización, asociados en muchos casos a la marginación -como sucede en Jurica-, representan un riesgo, porque son los que provocan que un lugar pierda su fuerza al dejar de tener significación y relevancia en términos de referente identitario para el grupo 
La construcción de la pertenencia socioterritorial: el caso de Jurica, un pueblo al que le llegó la ciudad

que lo habita. De esta preocupación se deriva la importancia que adquiere la investigación sobre los temas relacionados con la construcción de la identidad local como uno de los elementos a partir del cual se interrelacionan claramente el territorio y la cultura.

Lo que observé en Jurica es que a pesar de la urbanización, la identidad individual y la colectiva se (re)construyen en contraste con otros pueblos vecinos, con la ciudad y con la "colonia" (fraccionamiento campestre). El pueblo provee a los juriquenses de referentes identitarios de primer orden, como el entorno natural, su gente, tradiciones y costumbres, que lo hacen único. En este sentido, el pueblo cumple con una doble función, ya que al tiempo que es un marco territorial también es un marco histórico-cultural que trasciende a través de la memoria social.

Es posible hablar de Jurica como un pueblo porque los grupos que habitan ahí expresan un compromiso con su lugar, una voluntad y un deseo de la gente por pertenecer. En este orden de ideas, el pueblo es un espacio construido material, social y simbólicamente. El uso social del espacio y la relación de la gente con su entorno nos habla tanto de una identificación con el territorio como de un sentimiento de pertenencia originado por el hecho de saberse originarios de y arraigados en el lugar.

En Jurica la pertenencia se construye porque los habitantes del pueblo son capaces de diferenciarlo de otros lugares. Existen elementos materiales que contribuyen a ello (el entorno natural, las edificaciones, por ejemplo), pero también lo hacen las valoraciones y la construcción de una representación del lugar, la cual se conforma por los elementos que directamente perciben los sujetos, así como por los que les son heredados a través de la socialización. Es un lugar construido por los antepasados; un lugar en el que están inmersos cotidianamente, con el que están en contacto y, por ende, desde el cual perciben la ausencia de 
cambios o la escasez de estos, pues están familiarizados con él, lo cual ofrece una sensación de estabilidad, seguridad y calma. Dicha sensación se ve reforzada porque Jurica se concibe como un lugar vivido (Michel de Certeau, 2007); un lugar en donde la gente se conoce, comparten una memoria colectiva y una historia común. Lo que la gente más valora de su pueblo es su entorno natural, sus tradiciones y su gente (que se conoce entre sí). De esta manera se entretejen claramente el territorio y la cultura.

Fecha de recepción: 07 de marzo de 2013

Fecha de aceptación: 23 de julio de 2014

Bibliografía

Auge, Marc (1995). Los "no lugares”. Espacios del anonimato. Una antropología de la sobre modernidad. Barcelona: Gedisa.

De la Peña Guillermo,y Reneé de la Torre (1994).“Identidades urbanas al fin del milenio”, en Ciudades, abril-junio (pp. 24-3 I). México: Red Nacional de Investigación Urbana.

Castells, Manuel (200I). La era de la información, economía, sociedad y cultura. México: SIGLO XXI.

De Certeau, Michel (2007). La invención de lo cotidiano, I. Artes de hacer. México: ITESO.

Eliade, Mircea (1983). Lo sagrado y lo profano. Barcelona: Editorial Labor.

Flores, Julia Isabel, y Vania Salles (200I). “Arraigos, apegos e identidades: una acercamiento a la pertenencia socio territorial en Xochimilco", en María Ana Portal (coord.), Vivir la diversidad, identidades y cultura en dos contextos urbanos de México (pp. 63-I I5). México: UAM / CONACYT. García Canclini (2005). "La antropología en México y la cuestión urbana”, en García Canclini (coord.), La antropología urbana en México (Pp. I I-29). México:CONACULTA / FCE / UAM. 
La construcción de la pertenencia socioterritorial: el caso de Jurica, un pueblo al que le llegó la ciudad

Giménez, Gilberto (2007). Estudios sobre las culturas y las identidades sociales. México: CONACULTA / ITESO.

Guerrero Tapia,Alfredo (2007).“Imágenes de América Latina y México a través de los mapas mentales”, en Angela Arruda, y Martha De Alba (coords.), Espacios imaginarios y representaciones sociales (pp.235-284). México: Anthropos / UAM.

Hannerz, Ulf (1998). Conexiones trasnacionales, cultura, gente, lugares. Madrid:Ediciones Cátedra / Universidad deValencia.

Hiernaux Nicolas, Daniel, y Alicia Lindon (1993). "El concepto de espacio y el análisis regional”, Secuencia, 25 (pp. 89-II0). México: Instituto Mora.

Hoffmann, Odile, y Fernando I. Salmerón Castro (1997) (coords). Nueve estudios sobre el espacio: representación y formas de apropiación. México: CIESAS.

Icazuriaga Carmen, y Lorena Osorio (2007). “La relación periferia-centro en la ciudad de Querétaro mediante las prácticas de movilidad y consumo", Alteridades, enerojunio 33 (pp. 2 I-4I). México: UAM.

Ledrut, Raymond (1968). El espacio social de la ciudad. Buenos Aires:Amorrortu.

Licona Valencia, Ernesto (2007). Habitar y significar la ciudad. México: CONACYT / UAM.

Medina,Andrés (2007). "Los pueblos originarios del sur del Distrito Federal. Una mirada etnográfica”, en Andrés Media (coord.), La memoria negada de la Ciudad de México:sus pueblos originarios (pp. 29-124). México:UNAM. Mujica, María Constanza (2005). "Entrevista a Armando Silva: Ser santiaguino o porteño es, primero, un deseo”, Bifurcaciones, 4. Disponible en www.bifurcaciones.cl/004/Silva.htm Portal, y Patricia Safa (2005). “De la fragmentación urbana al estudio de la diversidad en las grandes ciudades", en Néstor García Canclini (coord.), La antropología urbana en México (PP. 30-59). México: CONACULTA / UAM / FCE. 
Lorena Erika Osorio Franco

Bibliografía $\quad$ Rapoport,Amos (1978). Aspectos humanos de la forma urbana. Editor GG.

Safa, Patricia (200I). Vecinos y vecindades en la ciudad de México. México: CIESAS.

Silva,Armando (2000). Imaginarios Urbanos. Colombia:Tercer Mundo Editores. 